\title{
Enhancement of Lithium Niobate nanophotonic structures via spin-coating technique for optical waveguides application
}

\author{
Makram A. Fakhri ${ }^{1 *}$, M.Halim A. Wahid ${ }^{2}$, Ban A. Badr ${ }^{3}$, Suad M. Kadhim², Evan T. Salim ${ }^{3}$, Uda Hashim ${ }^{4}$ and Zaid \\ T. Salim ${ }^{3}$ \\ ${ }^{1}$ Laser and Optoelectronic Department, University of Technology, 10001 Baghdad, Iraq \\ ${ }^{2}$ Semiconductor Photonics \& Integrated Lightwave Systems (SPILS), School of Microelectronic Engineering, University \\ Malaysia Perlis, Pauh Putra Campus, Arau 02600 Malaysia \\ ${ }^{3}$ Laser Science Branch, University of Technology, 10001 Baghdad, Iraq \\ ${ }^{4}$ Institute of Nano Electronic Engineering, University Malaysia Perlis, 01000 Kangar, Perlis, Malaysia
}

\begin{abstract}
This work is dedicated to investigation of temperature effects in Lithium Niobate (LiNbO3) nanostructures. The LiNbO3 nanostructures were deposited on glass substrate by spincoating technique. LiNbO3 was set down at $3000 \mathrm{rpm}$ for $30 \mathrm{sec}$ and annealed from 100 to $600{ }^{\circ} \mathrm{C}$. The structures were characterized and analyzed by scanning electron microscopy (SEM) and ultraviolet visible (UV-vis) spectrophotometer. The measured results have showed that by increasing annealing temperatures, the structures start to be more crystallized and be more homogenized until the optimum arrangement was achieved. Once this was accomplished, it's applicable for optical waveguides development. Eventually, it starts to be less crystallization and non-homogeneous. Energy gap was recorded to be at average value of $3.9 \mathrm{eV}$.
\end{abstract}

\section{Introduction}

Lithium Niobate (LN) is a very important optical material which is widely used by the photonics industry mainly due to its excellent electro/acousto-optical properties [1-3]. Lithium niobate $(\mathrm{LiNbO} 3)$ is an important ferroelectric material because of its excellent piezoelectrical, electrooptical, pyroelectrical and photorefractive properties $[4,5]$. It's widely used as a polar material for photonic applications $[6,7]$. In addition it's employed in nonlinear optics for frequency conversion and in telecommunication for electro-optic modulation $[8,9]$. Furthermore, it is an attractive material for the fabrication of optical wave-guide devices [10, 11]. Moreover, direct and indirect energy band gap of LiNbO3 is reported to be in the range of $3.5-4.7 \mathrm{eV}$ which depends on $\mathrm{LiNbO} 3$ concentrations. These changes are attributed to several parameters like grain size, composition and defects [12-14]. There are different known approaches to synthesize undoped LiNbO3 nanocrystals using soft-chemistry [15], pulsed laser deposition [16, 17], RF sputtering [18] and hydrothermal methods $[19,20]$. LiNbO3 is also studied in its heterojunction structure, photonic crystal and single phase thin film [21-25], and surface acoustic wave device (SAW) [26]. LiNbO3 waveguides are employed broadly in many functional electro-optic and acoustooptic devices [27]. The waveguide structures are essential in many integrated-optic devices especially at high frequency region.

This work reports the preparation of $\mathrm{LiNbO} 3$ nanostructures by exploiting the spin-coating technique. The characterization and analysis have been elaborated as a function of LN's annealing temperatures. The refractive index analysis is the main work on $\mathrm{LiNbO} 3$ optical waveguides because of refraction coefficients between the base and deposit samples will ensure access to total internal reflection that gives better realization of optical waveguides. The refractive index is measured and calculated in order to fit the best application of optical waveguides. Thus, the focus in the study is to prepare the LN thin film and to enhance towards a high quality film with optical properties closely like a single crystal $\mathrm{LiNbO} 3$ wafers.

\section{Experimental details}

LiNbO3 films were prepared mainly by adding $\mathrm{Nb} 2 \mathrm{O} 5$ (ultra-pure, 99.99\%) and citric acid (CA) without further purification. The solution was then mixed with $\mathrm{Li} 2 \mathrm{CO} 3$

* Corresponding author: mokaram_76@yahoo.com 
and Ethylene Glycol. The molar ratio between Li2Co3 and $\mathrm{Nb} 2 \mathrm{O} 5$ was $1: 1$ in order to maximize the formation of LiNbO3 stoichiometry phase. Firstly, the Li2Co3, $\mathrm{Nb} 2 \mathrm{O} 5$, and citric acid were dissolved in Ethylene Glycol with simultaneous heating and stirring at $90 \mathrm{oC}$ for 48 hours. Obtaining homogeneous and crack-free films of $\mathrm{LiNbO} 3$ requires the precursor to be deposited by spin coating technique on quartz substrates at a spinning speed of $3000 \mathrm{RPM}$ for $30 \mathrm{Sec}$ and $0.5 \mathrm{Ml} / \mathrm{L}$ molarity concentration. In total, seven layers were prepared.

The film was further dried at $120{ }^{\circ} \mathrm{C}$ for $5 \mathrm{~min}$ and calcined at $250{ }^{\circ} \mathrm{C}$ for $30 \mathrm{~min}$ in static air and oxygen atmosphere with the intention of removal the organics. Finally, the film was annealed from a constant step variation of 100 to $600{ }^{\circ} \mathrm{C}$. The structural evolution of the as-prepared thin films was examined using a highresolution X-ray diffraction (HR-XRD) system equipped with $\mathrm{Cu}$-K $\alpha$-radiation of wavelength $\lambda=0.15418 \mathrm{~nm}$ at $40 \mathrm{kV}$ and $30 \mathrm{~mA}$. The thickness of the annealed samples was measured using scanning optical reflectometery. The scanning electron microscopy (SEM) was employed to investigate the surface morphology of $\mathrm{LiNbO} 3$ and the atomic force microscopy (AFM) was utilized to observe the surface roughness of the LiNbO3 films. The optical properties were inspected by means of double-beam Ultra-Violet (UV-vis) spectrophotometer.

\section{Results and discussion}

\subsection{Morphological studies}

Figure 1 shows SEM images of $\mathrm{LiNbO}_{3}$ nanostructures deposited on quartz substrates at different annealed temperatures. The density of nucleation for the $\mathrm{LiNbO}_{3}$ thin films was not uniform on the flat substrate with dissimilar temperatures. At least molarity concentration notifies the emergence of a high proportion of the pores and voids. These pores were observed as a result of impurities impacts like $\mathrm{Nb}_{2} \mathrm{O}_{5}$. The $\mathrm{LiNbO}_{3}$ thin films grew smoothly at $500{ }^{\circ} \mathrm{C}$ that's led to good distribution better than other annealing temperatures as shown in Fig. 1. On the other hand, the structure is more homogenous at higher molar concentration [14]. This suggests that $500{ }^{\circ} \mathrm{C}$ leads to increase the regular distribution of $\mathrm{LiNbO}_{3}$ nano and micro structures. A closer examination of these samples indicates that our synthesized film like ice layers shape of morphology.

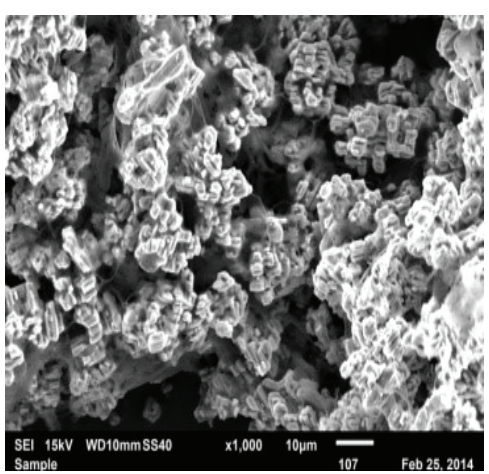

(a)

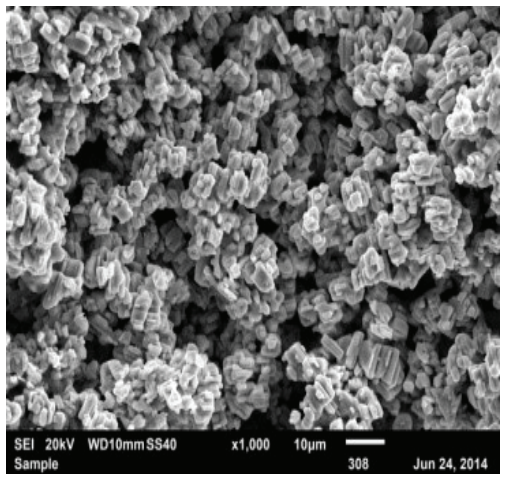

(b)

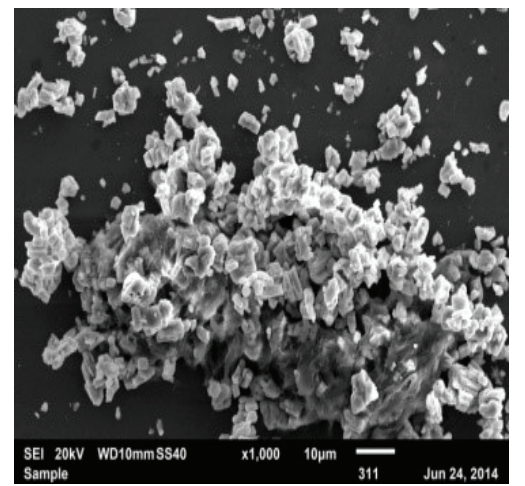

(c)

Fig. 1. Surface morphology of $\mathrm{LiNbO}_{3}$ nanostructures with different annealing temperatures. (a) $400{ }^{\circ} \mathrm{C}$, (b) $500{ }^{\circ} \mathrm{C}$, and (c) $600{ }^{\circ} \mathrm{C}$

\subsection{Optical properties}

The transmission spectra of $\mathrm{LiNbO}_{3}$ nanostructures at different annealing temperatures are shown in Fig. 2. It was measured that the transmission increased with the annealing temperature. This may be due to the increasing of grain size and decreasing thickness. Similar result was also recorded in other work [28]. The values of transmission were about $70-80 \%$ with the annealing temperature range of 100 to $600{ }^{\circ} \mathrm{C}$. The deposited samples were white to brown in color and showed high transmittance. The high value of transmittance is attributed to the excessive $\left(\mathrm{LiNbO}_{3}\right)$ ions at interstitial site that increased its transparency level. 


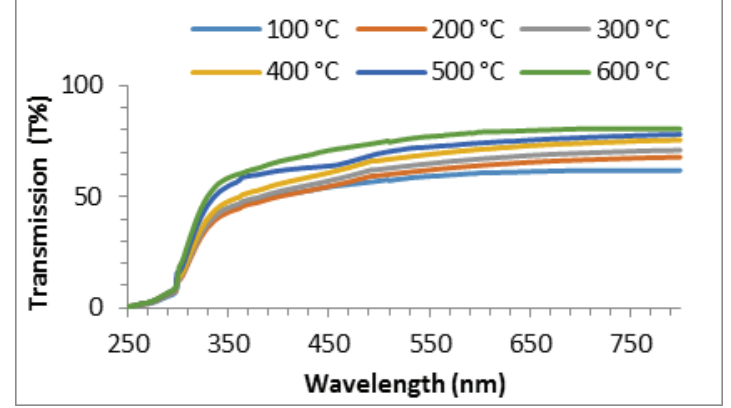

Fig. 2. Transmission spectra of $\mathrm{LiNbO}_{3}$ nanostructures at different annealing temperatures

Figure 3 shows the reflectance of $\mathrm{LiNbO}_{3}$ nanostructures in the wavelength range of $250-800 \mathrm{~nm}$ at room temperature. The reflection spectra were found to decrease with annealing temperature due to the increment in the surface roughness that related to crystals grain size.

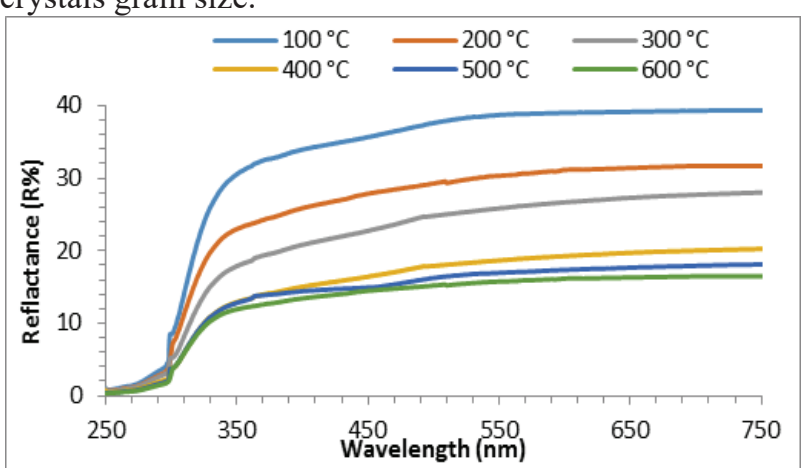

Fig. 3. Reflection spectra of $\mathrm{LiNbO}_{3}$ nanostructures at different annealing temperatures

The energy band gap $\left(E_{g}\right)$ was established as a function of photon energy in Fig. 4. All curves were singularized at a specific point around $3.25 \mathrm{eV}$. However, the $\mathrm{E}_{\mathrm{g}}$ was extrapolated and recorded at different values. The value was noted to increase with annealing temperatures due to shrinkage in the grain size.

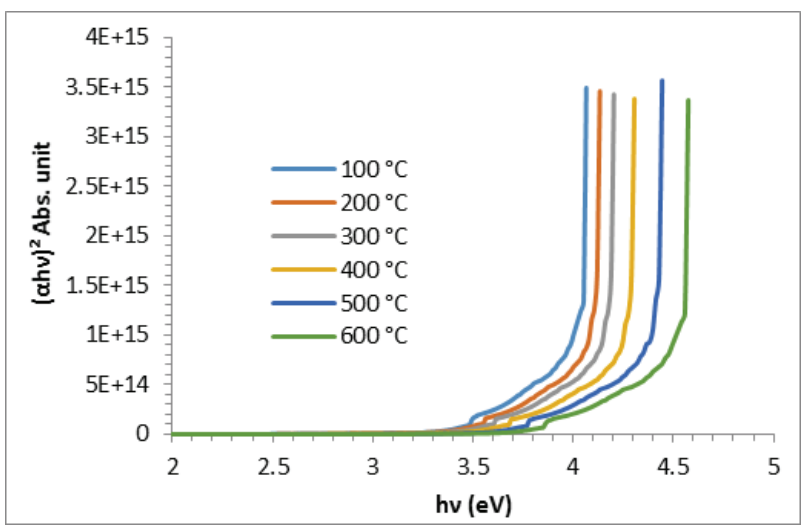

Fig. 4. Energy band gap of $\mathrm{LiNbO}_{3}$ nanostructures at different annealing temperatures

The refractive index (n) was determined from a transmittance spectrum as a function of the wavelength at different annealing temperatures. The spectrum showed that there was a decrease in the refractive index with incident wavelength from 2.32 to 2.56 which related to the drop in the reflectance as depicted in Fig. 5.

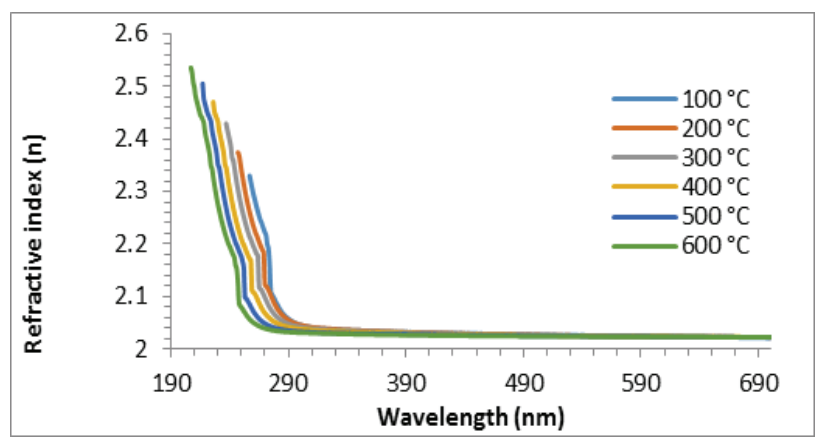

Fig. 5. Refractive index of $\mathrm{LiNbO}_{3}$ nanostructures at different annealing temperatures

Beside that an increment in the refractive index could be realized in the UV region with the annealing temperature as shown in Fig. 6. This behavior may be incorporated to growth in packing density as a result of the oxidation process during heat treatment. All the higher values of refractive index are suitable for optical waveguide fabrication.

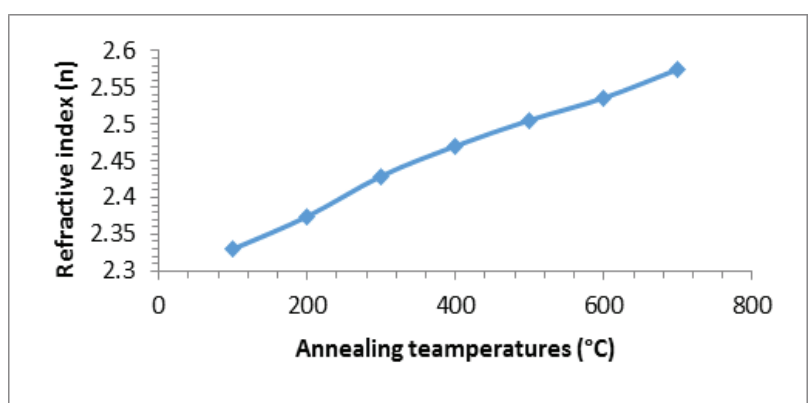

Fig. 6. Refractive index with concentration of $\mathrm{LiNbO}_{3}$ nanostructures at different annealing temperatures

\section{Conclusion}

The LiNbO3 nanostructures have been chemically prepared by spin-coating technique. SEM shows diameter of grain size from 64 to $167 \mathrm{~nm}$. Optical properties give high values of transmission which is about $89-96 \%$ and the measured energy band gaps are 3.6, 3.85, 4 and $4.2 \mathrm{eV}$. We found an approximate match between the energy band gap in the values calculated using the transmission spectra. The refractive index is determined from the transmission spectrum and established its appropriateness for application in optical waveguides that needs high value.

\section{References}

1. Makram A. Fakhri, Y. Al-Douri, U. Hashim and E. T. Salim, Australian Journal of Basic and Applied Sciences 9, 128-133 (2015).

2. Makram A Fakhri, Y Al-Douri, Uda Hashim and Evan T Salim, Advanced Materials Research 1133, 457-461 (2016). 
3. Evan T. Salem, Surface Review and Letters 20, 1350046-1-1350046-6 (2013).

4. J. Zhang and X. Zhang, Optics Communications 320, 56- 59 (2014).

5. L. Cao, A. Aboketaf,Z. and Wang,S. Preble, Optics Communications 330, 40-44 (2014).

6. H. Chen, , T. Lv, A. Zheng and Y. Han, Optics Communications 294, 202-207 (2013).

7. P. Ganguly, Optics Communications 285, 43474352 (2012).

8. B. Knabe, D. S. Tze, T. Jungk, M. Svete, W. ssenmacher, W. Mader and K. Busem, Status Solidi (a) 208, 857-862 (2011).

9. S. Mamoun , A.E. Merad and L. Guilbert, Computational Materials Science 79, 125-131 (2013).

10. C. Thierfelder, S. Sanna, A. Schindlmayr, and W. G. Schmidt, Phys. Status Solid (C) 7, 362-365 (2010).

11. A. Tumuluri, K .L. Naidu and K.C.JamesRaju, International Journal of Chem Tech Research CODEN (USA): IJCRGG 6, 3353-3356 (2014).

12. O. P. Nautiyal1 and S. C. Bhatt, American Journal of Materials Science 1, 1-4 (2011).

13. Makram A. Fakhri, Y. Al-Douri, U. Hashim, Evan T. Salim, Deo Prakash and K. D. Verma, Applied Physics B 121, 107-116 (2015).

14. Makram A. Fakhri, U. Hashim, Evan T. Salim and Zaid T. Salim, J Mater Sci: Mater Electron 27, 13105-13112 (2016).

15. M.Liu, D Xue and K Li, Journal of Alloys and Compounds 449, 28-31 (2013).

16. X. Wang, Y.Liang, S. Tian, W. Man and J. Jia, Journal of Crystal Growth 375, 73-77 (2013).

17. Makram A Fakhri, Y Al-Douri, U Hashim and Evan T Salim, Solar Energy 120, 381-388 (2015).

18. V. Iyevlev and A. Kostyuchenko, Journal of Materials Science: Materials in Electronics 22, 1258-1263 (2011).

19. Evan T. Salim, International Journal of Nanoelectronics and Materials 5, 95-100 (2012).

20. M. Aufray, S. Menuel, Y. Fort, J. Eschbach, D. Rouxel and B. Vincent, Journal of Nanoscience and Nanotechnology 9, 4780-4785 (2009).

21. Evan T. Salim, Indian Journal of Physics 87, 349353 (2013).

22. Y. Guo, Ch. Divin A. Myc, F. L. Terry, J.R. Baker, T. B. Norris, and J. Y. Ye, Opt. Express 16, 1174111749 (2008).

23. H. Lu, B. Sadani, G. Ulliac, N. Courjal, C. Guyot, J. -M. Merolla, M. Collet, F. I. Baida, and M.-P. Bernal, OPTICS EXPRESS, 20, 20884-20893, (2012).

24. J. Son, S. S. Orlov, B. Phillips, L.Hesselink, Journal of Electroceramics, 17, 591-595, (2006).

25. AbdulhadiKadhim, Evan T. Salim, Saeed M. Fayadh, Ahmed A. Al-Amiery, Abdul Amir H. Kadhum, and Abu BakarMohamad, The Scientific World Journal, Article ID 490951, 6 page (2014).

26. K.S. Kao, C.C. Cheng, Y.C. Chen, Y.H. Lee, Applied Physics A, 76, 7, 1125-1127, (2003).
27. G-h. Shao, X-s.Song, F. Xu, and Y-q. Lu1, OPTICS EXPRESS , 20, 19343-19348, (2012).

28. Ibrahim R. Agool, Evan T. Salem, Marwa A. Muhsien, International Journal of Modern Physics B, 25, 1081-1089, (2011).

29. Z. T Salim, U Hashim, MKM Arshad, Makram A.Fakhri, ET Salim, Materials Research Bulletin 86, 215-219, (2017).

30. Evan T Salim, Marwa S Al Wazny, Makram A Fakhry, Modern Physics Letters B, 27, 1350122-71350122-1, (2013).

31. David E. Zelmon and D. L. Small, J. Opt. Soc. Am. B, 14, 3319 - 3322, (1997).

32. T.Ghosh, B.Samanta ,P.C. Jana, and P. Ganguly, Fiber and Integrated Optics, 31, 1-10, (2012).

33. D.L. Zhang, Q. Zhang, C.X. Qiu, W.H. Wong, E. Y. B. Pun, Optical Materials Express, 4, 2215 2220, (2014).

34. S. Nakamura, Mukai, T., Senoh, M., Jpn. J. Appl. Phys. 30 L1705, (1991). 